\title{
Geological and Geophysical Factors Constraining the Occurrence of Earthquake Precursors in Geofluids: A Review and Reinterpretation
}

\author{
Giovanni Martinelli ${ }^{1,2,3}$ and Giancarlo Tamburello ${ }^{4 *}$ \\ ${ }^{1}$ Istituto Nazionale di Geofisica e Vulcanologia, Sezione di Palermo, Palermo, Italy, ${ }^{2}$ Institute of Eco-Environment and Resources, \\ Chinese Academy of Sciences, Lanzhou, China, ${ }^{3}$ Laboratory of Petroleum Resources Research, Institute of Geology and \\ Geophysics, Chinese Academy of Sciences, Lanzhou, China, ${ }^{4}$ stituto Nazionale di Geofisica e Vulcanologia, Sezione di Bologna, \\ Bologna, Italy
}

OPEN ACCESS

Edited by:

Pascal Audet,

University of Ottawa, Canada

Reviewed by:

Heiko Woith,

German Research Centre for

Geosciences, Helmholtz Centre

Potsdam, Germany

Adnan Barkat,

National Center for Physics, Pakistan

*Correspondence:

Giancarlo Tamburello

giancarlo.tamburello@ingv.it

Specialty section:

This article was submitted to

Solid Earth Geophysics,

a section of the journal

Frontiers in Earth Science

Received: 18 August 2020 Accepted: 23 November 2020 Published: 23 December 2020

Citation: Martinelli G and Tamburello G (2020) Geological and Geophysical Factors Constraining the Occurrence of Earthquake Precursors in Geofluids: A

Review and Reinterpretation.

Front. Earth Sci. 8:596050.

doi: 10.3389/feart.2020.596050
In this paper, we update the previous compilations of observed earthquake precursors from the published scientific literature of the last decade. We collected the epicentral coordinates, magnitude, hypocentral depth of each earthquake and the distance from the observed precursor and its time lag. The locations are reported and compared with data concerning geological and geophysical parameters like global seismicity, volcanic locations, heat flow and tectonic regimes. Possible relations between geological and geophysical parameters and the occurrence of fluid-related earthquake precursors are considered and discussed. Some geological and geophysical conditions can be deemed responsible for the occurrence of fluid-related earthquake precursory phenomena. Geophysical models used to explain the occurrence of earthquake precursors are discussed with the purpose of contributing to engineering proper monitoring networks. Areas of the world potentially suitable for earthquake fluid-related precursor monitoring are suggested.

Keywords: seismic precursor, earthquakes, geofluids, ground deformaticn, b-value, heat flow, catalog

\section{INTRODUCTION}

Many possible earthquake precursors have been used in research to describe and understand the physical and chemical processes occurring in the Earth's crust in the phases preceding earthquakes. The majority of the observed precursors are related to underground fluids. Fluid parameters are still widely studied in this research topic due to their physical and chemical peculiarities. Groundwater is scarcely compressible; thus, it may act as a natural strainmeter when the reservoir is confined (Bodvarsson, 1970; Roeloffs, 1988; Matsumoto et al., 2007), and its chemical composition may provide valuable information on fluid movements in the crust.

Water is essentially incompressible (Fine and Millero, 1973), thus, water pressure may be considered a sensitive indicator of strain when measured in confined reservoirs (Bodvarsson, 1970). Water level and water flow rate may be considered the most relevant parameters capable of revealing eventual pore pressure variations in confined reservoirs. Positive temperature variations may also be considered indicators of mass transport phenomena in deep confined reservoirs capable of revealing future pore pressure fluctuations induced by crustal deformation processes. Parameters directly involved in crustal deformation processes are ground deformations (light blue circles in 


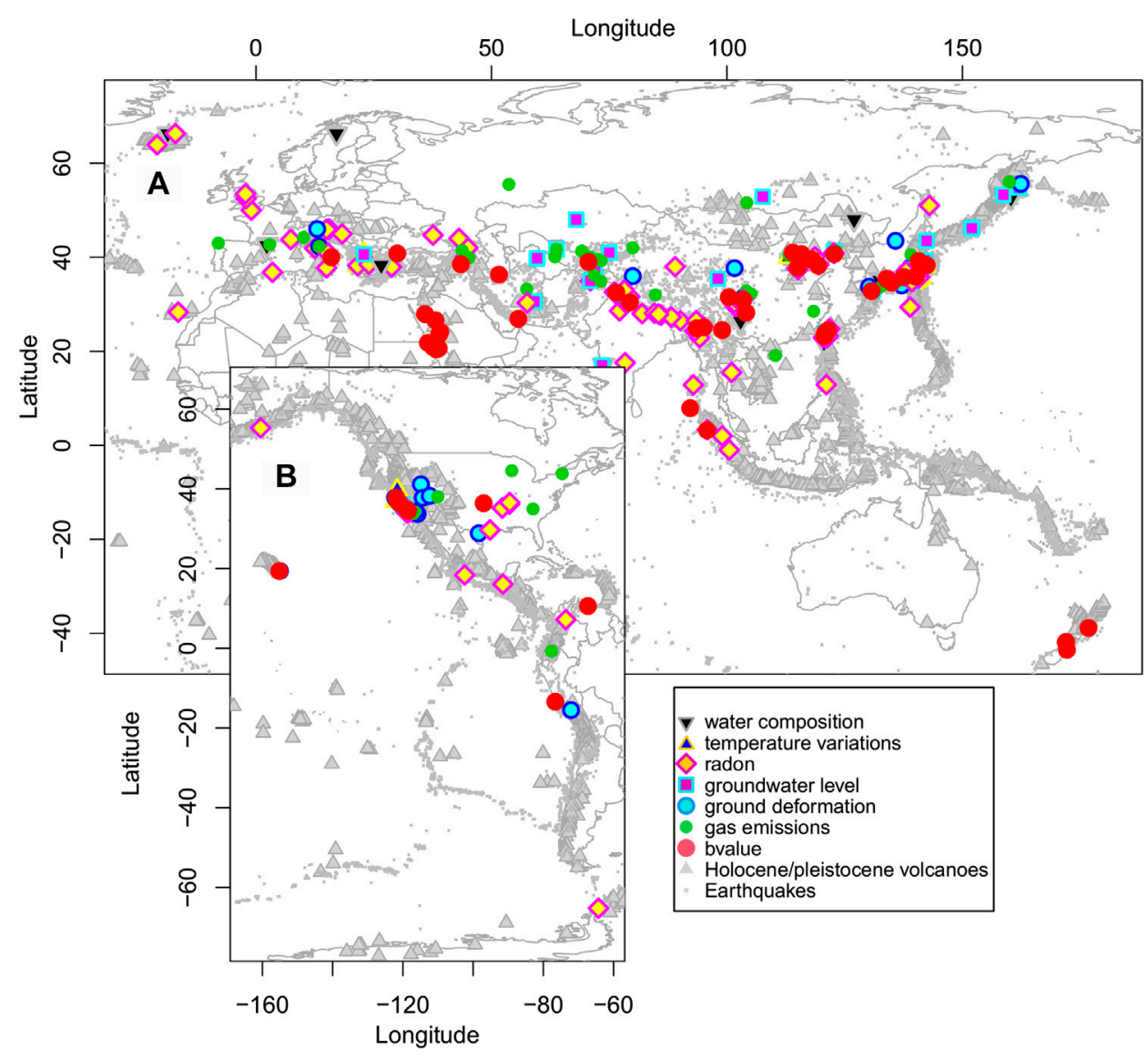

FIGURE 1 | Global distribution of the seismic precursors cataloged in this work and divided into seven typologies. Holocene/Pleistocene volcanoes and earthquakes from the ISC catalog are also shown.

Figures 1,2) and b-value (red circles in Figures 1,2). Water level variations are induced by possible pore fluid fluctuations generated by crustal deformative processes. The water level is recognized as a highly sensitive parameter (e.g. Kumpel, 1992). Possible deep fluid pressure variations due to crustal deformations are considered proportional to the stress and volumetric strain. The stress-strain relationship for anisotropic, linearly elastic porous medium, was proposed by Rice and Cleary (1976). The stress tensor $\sigma_{\mathrm{kk}}$, the volumetric strain $\varepsilon_{\mathrm{kk}}$ and the fluid pressure $\mathrm{P}$ under undrained conditions have been described as follows:

$$
\begin{gathered}
P=-B \sigma_{k k} / 3, \\
P=-2 G B\left(1+v_{u}\right) \varepsilon_{k k} / 3\left(1+v_{u}\right),
\end{gathered}
$$

where $G$ is the shear modulus, $B$ is the Skempton coefficient, and $v_{u}$ is the Poisson's ratio under undrained conditions. Groundwaters in confined aquifers can be thus utilized as natural strainmeters, with water being considered nearly incompressible (e.g. Matsumoto et al., 2007 and references therein). Fluid pressure is proportional to stress and volumetric strain. In particular, the water level can be used as the signal of a natural sensitive $\left(10^{-7}-10^{-8}\right)$ process during ongoing deformation. Possible fluctuations of water level have been recorded at very long distances (up to $300 \mathrm{~km}$, Figure 2) compared to ground deformations and b-value. Gases are, instead, compressible and if compared to data from strain meters, cannot give unequivocal results (Roeloffs, 2006 and references therein). Calculation of the stress tensor from a gas like radon, helium, $\mathrm{CO}_{2}$ or $\mathrm{CH}_{4}$ is an unresolved challenge. However, data from gases can be utilized to semiquantitatively track tectonic activity in geodynamically active zones.

Deep gases may also provide information about deep fluid migration processes toward the earth surface (e.g. Thomas, 1988). In light of these features, in the last decades, underground fluid monitoring has been carried out by the scientific community together with other geophysical parameters in order to record earthquake precursors. This idea has become predominant in almost all recent research projects on earthquake precursors. In particular, researchers consider that the dynamics of deep fluids can be influenced by crustal deformative processes, especially before seismic events. Hence, geochemical and hydrogeologic data are compared with data related to crustal deformation, such as geodetic and seismic data. However, potential fluid-related precursory phenomena are not always detectable (Kumpel, 1992). 


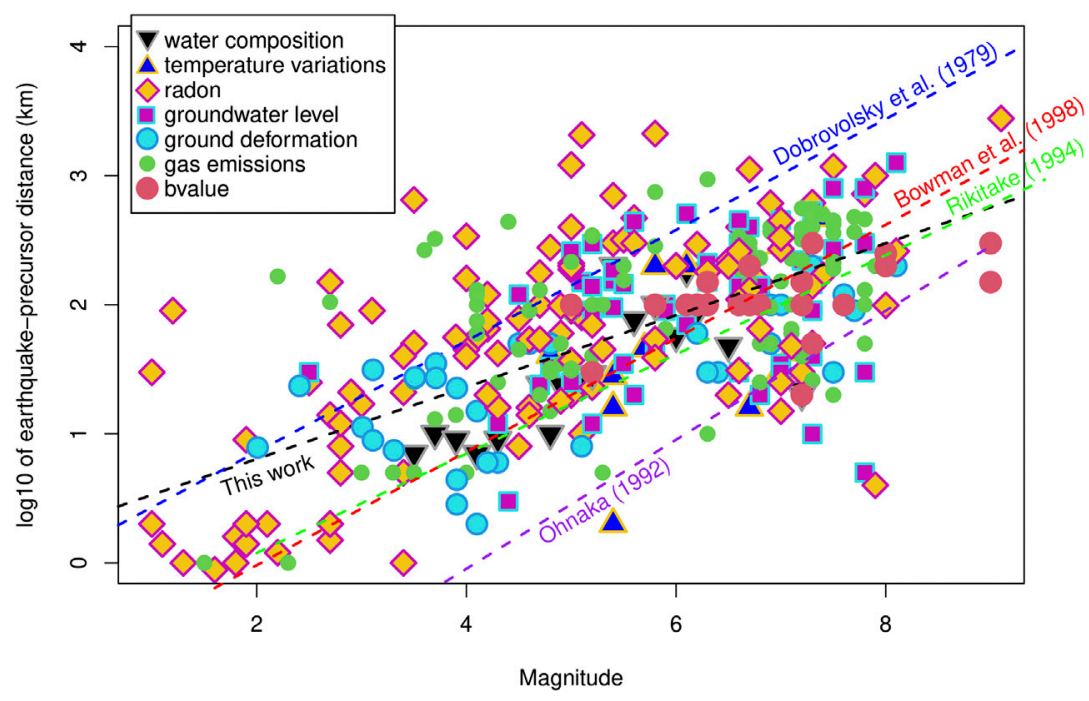

FIGURE 2 | Scatter plot of magnitude vs logarithm of the earthquake-precursor distance for all the seismic precursors cataloged in this work. The blue, green and gray lines are the earthquake-precursor distance vs magnitude relation suggested by Dobrovolsky et al. (1979), Rikitake (1994) and Ohnaka (1992) respectively. The red line is the critical region radius (radius of the earthquake preparation area) vs magnitude proposed by Bowman et al. (1998). The black line is the empirical best fit of the data cataloged in this work.

Many earthquakes occur in areas where underground fluids are inaccessible; thus, indirect methods to monitor pore pressure fluctuations in geofluids have been developed. These methodologies include magnetotelluric stations (Ping et al., 2018), ambient seismic noise (Chaves and Schwartz, 2016), and b-value estimate (Wang, 2016). Future research projects on earthquake precursors should be focused in areas where the detectability of possible precursors is higher (Martinelli, 2020).

The purpose of the present work is to update the previous compilation of seismic precursors and explore the possible existence of constraining factors promoting of fluid-related precursory signals. For this purpose, we compare our updated dataset of seismic precursors with other geological datasets, in particular heat flow and global seismicity.

\section{UPDATED CATALOG OF PRECURSORY SIGNALS}

Compilation of catalogs containing metadata on seismic precursors from previous publications can help researchers to understand when and where possible precursory phenomena have occurred. Indeed, in the last two decades, many catalogs of earthquakes and related precursory phenomena have been compiled by different authors. Hauksson (1981) reviewed all the available radon precursory anomalies throughout the world published in the period 1971-1981. Friedmann (1985) reviewed all available radon precursory anomalies published in the period 1969-1982. Toutain and Baubron (1999) reviewed the gaseous anomalies published in the period 1980-1995. Kissin and Grinevsky (1990) reviewed the available anomalies in water level data in the period 1948-1980. Hartmann and Levy (2005) reviewed gaseous and water-related anomalies published in the period 1978-1997. Cicerone et al. (2009) reviewed the geochemical, hydrogeological and geophysical anomalies that occurred in the period 1948-2001. Ghosh et al. (2009) reviewed radon data recorded in many parts of the world in the period 1983-2002. Petraki et al. (2015) reviewed radon data recorded all around the world in the period 1966-2014. Woith (2015) reviewed radon data recorded all around the world in the period 1967-2014. All of the works mentioned above directly or indirectly recognized that crustal deformative processes (see also Bernard, 2001; Wang and Manga, 2010) are responsible for observed fluid-related anomalies; thus, further catalogs of geophysical precursors related to crustal deformations could be useful for understanding fluid anomalies recorded before earthquakes. Roeloffs (2006) reviewed precursory deformative anomalies published from 1979 to 2004, whereas Cicerone et al. (2009) reviewed, among other things, precursory ground deformation anomalies published in the years 1974-1999. A merging of mentioned catalogs has been performed by Martinelli and Dadomo (2017) with complementary data published in the period 2009-2016 on peer-reviewed scientific journals. In the present work, we updated the catalog of seismic precursors (see Supplementary Table S1 in Supplementary Material) by adding further data to the previous work of Martinelli and Dadomo (2017), such as possible precursory ground deformations data recorded in the period 2009-2019. Yamashita and Tsutsumi (2018) recognized the role of geofluids in earthquake generation and triggering. Wang (2016) reported that pressurized geofluids might strongly influence b-value possible fluctuations before earthquakes. Wang et al. (2016) reviewed places in the world where b-value possible precursory fluctuations were observed in the period 1970-2008. Possible variations in b-value over time might be 
related to pore pressure variations at depth driven by geofluids influenced by crustal deformation processes. Possible precursory variations in b-value could be considered as an indication of fluctuations in geofluids in selected areas. We added in our updated catalog also the precursory b-value anomalies published for the period 2009-2019 by Wang et al. (2016). At the time of writing, we believe in having achieved an updated catalog of fluid-related seismic precursors, with the relatively poorly discussed precursory b-value. The considered period is 1948-2019 (see Supplementary Table S1 in Supplementary Material and references therein). In Figure 1, we show the global distribution of the seismic precursors collected in this work. The majority of them cluster around active margins characterized by intense seismic and volcanic activity.

\section{DATA SELECTION OF EARTHQUAKE PRECURSORS}

A "seismic precursor" is a quantitatively measurable variation of an environmental parameter that occurs before a mainshock, and that is linked to the preparation process for the seismic event (Wyss, 1991). Recent studies have demonstrated that the nucleation time of earthquakes occurs in the range $0.5-10 \mathrm{~s}$ (Beroza and Ellsworth, 1996; Ma et al., 2002; Fang et al., 2010) while the slip displacement at the nucleation zone is in the range $0.01-5 \mathrm{~m}$ (Ohnaka, 2000). Rock permeability is in the range $10^{-18}-10^{-15} \mathrm{~m}$ at a depth of $10-20 \mathrm{~km}$ (Gleeson and Ingebritsen, 2017). These constraining parameters led Albarello (2015), Woith et al. (2018) and Martinelli (2020) to propose that eventual precursory signals recorded in geofluids and as ground deformation may be considered as an indicator of the stress field evolution over time rather than signals generated by a hypothetical focal volume of a forthcoming seismic event.

Thus, large-scale deformation processes may easily affect fluid reservoirs while it is hard to believe in an active role of a single forthcoming seismic source. All the signals have been simultaneously recorded with a seismic event to which authors have associated possible precursory fluctuations in parameters usually considered in monitoring geofluids like water level, radon, water temperature, water chemical composition and gas composition. Precursory ground deformations recorded in the period 1974-2020 (Roeloffs, 2006; Cicerone et al., 2009 and the present work) and b-value precursory variations recorded in the period 1973-2020 (Wang et al., 2016 and the present work) have been also included in the data set considered in Figure 1 (see also Supplementary Material SA). While the magnitude was always reported in the examined studies, the distance was not always specified and, thus, we tried to extrapolate from other information. For the precursory b-values works we took as a distance the average diameter of the studied area where b-values have been calculated. We are confident that our interpretation of the distances may provide at least a correct order of magnitude.

Woith (2015) suggested that selecting only seismic precursor data characterized by a years-long time series of precursory signals, together with environmental data, would reveal substantial differences in data quality and reliability. However, this more complex selection lies beyond the scope of the present paper and should be performed in further review steps. We are confident that the unreliable seismic precursors accidentally selected in our catalog contribute to an overall error that will not affect our analysis and conclusions. Finally, in this work we did not carried out a case-by-case quality check on the dataset that could contain false positive cases.

In Figure 2, we plot the magnitude and distance intervals of the fluid-related precursors listed in this work. The scatter plot shows also a slightly positive correlation between the precursorearthquake distance and the magnitude of the possibly linked forthcoming mainshock. The link between these two parameters has already been discussed in previous works (Dobrovolsky et al., 1979; Bowman et al., 1998; Rikitake, 1994; Figure 2). We tentatively used the data of this catalog to best-fit the points with an exponential function and compare the results obtained with previous models:

$$
D=10^{(0.28 M+0.25)}
$$

where $D$ is the precursor-earthquake distance in $\mathrm{km}$ and $M$ is the magnitude of the seismic event. The presence/absence of our approximated b-value precursor-earthquake distances does not affect the calculated coefficients. The obtained empirical coefficients $(a=0.28, b=0.25)$ are different from the ones obtained by Dobrovolsky et al. (1979) and Bowman et al. (1998) $(\mathrm{a}=0, \mathrm{~b}=0.43$ and $\mathrm{a}=-0.9, \mathrm{~b}=0.44$ respectively). This difference may be due to the presence in the catalog of likely unreliable seismic precursors characterized by low earthquake magnitudes and great earthquake-precursor distances. However, it would still confirm that crustal deformative processes are responsible for eventual precursory signals recorded in geofluids in the earthquake preparation area.

It is worthwhile to note that anomalous fluctuations not followed by an earthquake could have also been recorded, although not always reported or commented. These signals are often disregarded in the scientific literature and sometimes considered as "false alarm" but may help us to understand that a presumed precursor is an indicator of a nowcasting situation of a deforming rock which could, or could not, be followed by a relevant shock. In other words crustal dynamic often induce crustal deformative processes. Great part of the deformation follows small or big seismic events. A small part of the deformation may precede a seismic sequence in aseismic way or throught small seismic events, particularly in extensional geological environments. The spatial localization of a possible forthcoming seismic event could be better constrained by complementary geophysical parameters capable of better identifying the stress evolution during the time in the studied geological formations (Utsu, 2002 and references therein; Tiampo and Shcherbakov, 2012 and references therein). The recorded fluctuations in parameters related to geofluids (including b-value) and rock deformations (Figures 1,2) coincide with rock volumes that underwent possible accelerations in crustal deformative processes. The present state of the art in geofluid monitoring allows for sensitive nowcasting of tectonic pumping phenomena. However, details about the evolution of the identified process 


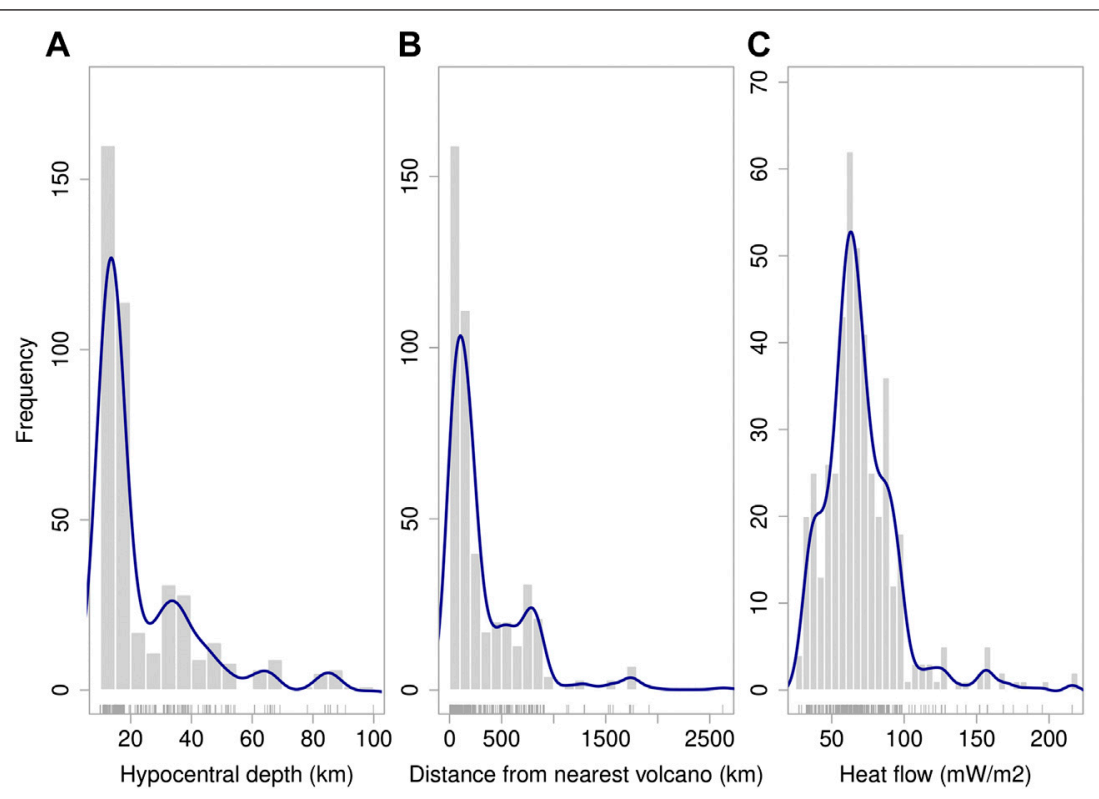

FIGURE 3 | Frequency histogram (over 453 total cases) of (A) average hypocentral depths, (B) distances from the nearest volcano and (C) heat flow values associated with each cataloged seismic precursor.

during time and space could eventually be derived from the analysis of data recorded by dense networks and by the analysis of further geophysical parameters (Chebrov et al., 2013; Huang et al., 2017).

Further relevant details could be revealed by the geographic distribution of considered data and by the analysis of local geophysical parameters. In particular, local geophysical parameters allow recognizing most deformable geological formations during pre-seismic stages and the most suitable sites where geophysical conditions useful for observing and recording eventual earthquake precursors in geofluids could be identified.

\section{FACTORS POTENTIALLY CONTROLLING THE DISTRIBUTION OF SEISMIC PRECURSORS}

Previous researches have evidenced that a significant part of the precursory signals was recorded in extensional areas (Cicerone et al., 2009; Martinelli and Dadomo, 2017; Supplementary Figure S2 in Supplementary Material). Recent data sets published by Lucazeau (2019), Di Giacomo et al. (2018) and the International Seismological Center (2020) have allowed us to constrain further the geodynamic environment where the "occurrence of earthquake precursors" has a high probability. We assigned to each precursor of our catalog the spatially correspondent heat flow value (Lucazeau, 2019; see Supplementary Figure $S 1$ in Supplementary Material), average hypocentral depth (within a search radius of $100 \mathrm{~km}$ ) and distance from the nearest Holocene/Pleistocene volcano (Global Volcanism Program, 2013). The frequency distributions of these parameters show that $\sim 60 \%$ of the seismic precursors have average seismic hypocentral depth $<20 \mathrm{~km}$, occurred in areas with heat flow $>65 \mathrm{~mW} \cdot \mathrm{m}^{-2}$, and have the nearest volcano at less than $\sim 215 \mathrm{~km}$. We choose the $60 \%$ value because it approximately corresponds to the abrupt increase of hypocentral depths and distances from volcanoes in the frequency histograms in Figure 3.

We used these results as threshold values for our following processing. We calculated the kernel density, that is an estimation of the number of points per unit area (Diggle, 1985), of the distribution of the shallow earthquakes (hypocentral depth $<20 \mathrm{~km}$ ) only in areas characterized by relatively high heat flux $\left(>65 \mathrm{~mW} \cdot \mathrm{m}^{-2}\right)$. The map in Figure 4a shows that most of the precursory signals were recorded in areas of a high density of shallow seismic activity and high heat flux. Holocenic and Pleistocenic volcanoes are also shown in Figure $\mathbf{4}$ as indicators of the presence of geofluids in the crust. These areas are also characterized by extensional tectonics (Supplementary Figure S2 in Supplementary Material) where relatively soft rocks (Ranalli, 1995; Scholz, 2010) would allow possible crustal deformative processes before and after strong shocks. An analysis of the kernel density of deeper earthquakes (hypocentral depth $\geq 20 \mathrm{~km}$, ISC, 2020) do not show the same spatial correspondence with seismic precursors (see Supplementary Figure S3 in Supplementary Material).

The seismicity of the Earth occurs at depths where rocks exhibit brittle behavior, while earthquakes are absent in the deeper layers where rocks exhibit ductile behavior and deformations are about aseismic (e.g. Dragoni, 1993 and references therein). Typically, lithospheric rocks are modeled as Maxwell viscoelastic materials (e.g. Burov, 2011) with temperature-dependent viscosity, depending on the depth of 


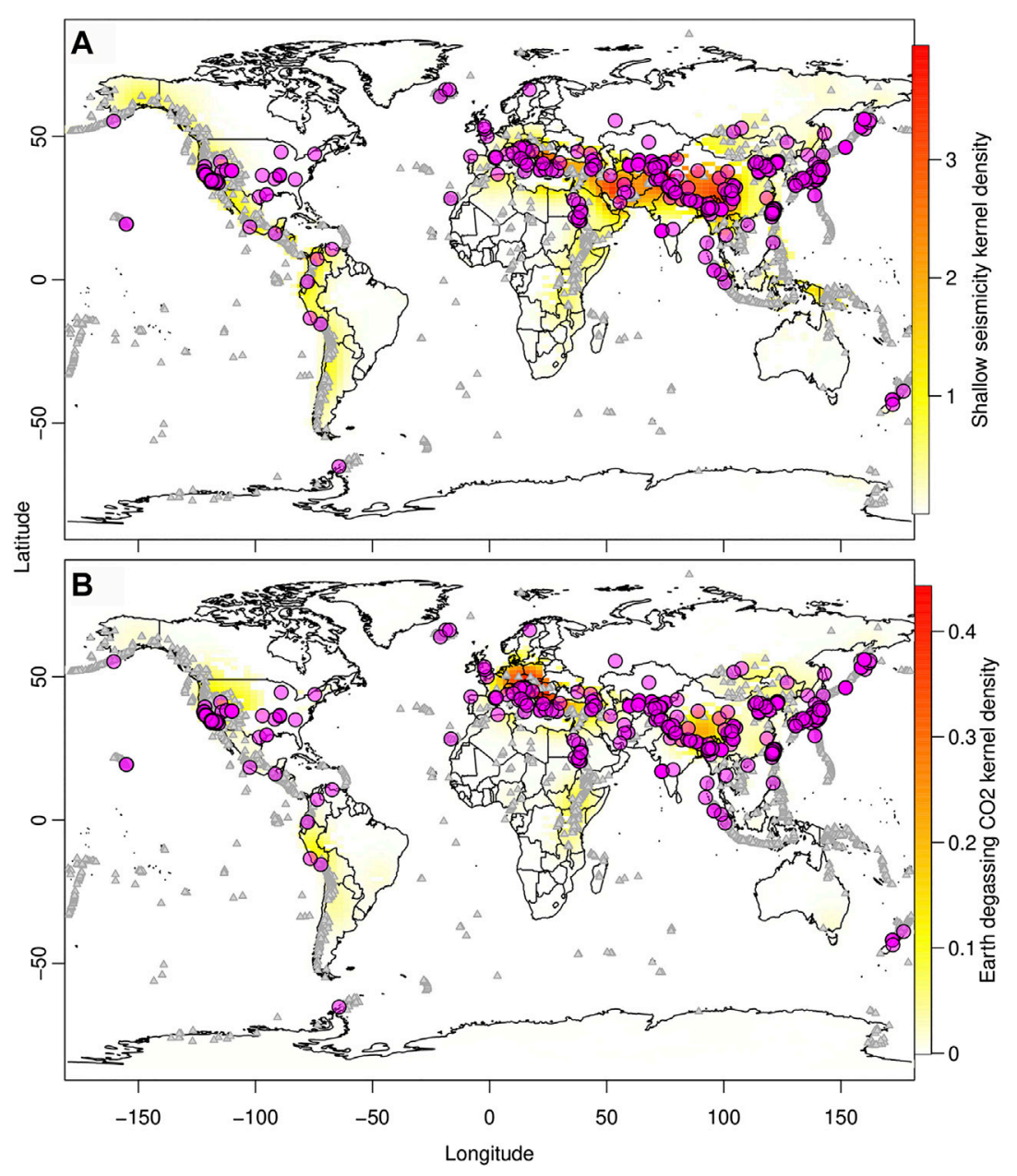

FIGURE 4 | Kernel density maps of (A) shallow (hypocentral depth $<20 \mathrm{~km}$ ) seismic activity and (B) areas characterized by Earth degassing of $\mathrm{CO}_{2}$. Seismic precursors are shown as purple circles and Holocene and Pleistocene volcanoes as small red triangles.

the brittle-ductile transition from strain rate, stress and temperature (Chen and Molnar 1983; Sibson, 1983; Dragoni 1993). Possible b-value variations and eventual pre-earthquake deformations could fail to occur below brittle seismogenic depths (Ohnaka, 1992; Roeloffs, 2006). Most favourable conditions for shallow depth seismicity occur in areas evidenced in Figure 4 in which heat flux values are particularly high and where the possible presence of geofluids at depth, particularly water and $\mathrm{CO}_{2}$, may reduce shear resistance and induce frictional sliding (Chiodini et al., 2004; Heinicke et al., 2009; Collettini et al., 2011; Bürgmann, 2018). The proximity of Holocene/Pleistocene volcanoes provides us with a supplementary indicator of the presence of underground fluids.

Most relevant identified areas include Greece, Italy, Turkey, Israel, part of Northern Africa, the Caucasian belt, Tajikistan, Iran, Pakistan, parts of India and Nepal, China, Japan, Taiwan, Kamchatka, New Guinea, New Zealand, Central America, California and the western side of Latin America. According to Heidbach et al. (2018), all these areas are located in geological environments characterized by extensional and strike-slip tectonic regimes (Supplementary Figure S2 in Supplementary Material). Significant strain rates $\left(>5 \cdot 10^{-9} \mathrm{yr}^{-1}\right)$ have been observed in all described areas (Kreemer et al., 2003; Kreemer et al., 2014). Relatively high strain rates may enhance crustal permeability values and allow intense circulation of geofluids which, in turn, may be affected by precursory pore pressure fluctuations, geochemical variations, temperature variations and gaseous emissions. Sammonds et al. (1992) and Wang (2016) reported that pressurized geofluids might influence the b-value of an area before an earthquake. In our catalog, we reported the cases in which precursory b-value fluctuations have been observed before relevant shocks, confirming that this parameter may be considered and evaluated together with geofluids, as shown in Figure 2.

The most important geofluids continuously expelled by the Earth are water, $\mathrm{CO}_{2}$ and $\mathrm{CH}_{4}$ (Fyfe et al., 1978). In particular, carbon dioxide is generated by deep geological processes like mantle degassing, thermo-metamorphic and mechanochemical reactions (Frezzotti et al., 2009; Werner et al., 2019). Tamburello et al. (2018) showed that $\mathrm{CO}_{2}$ rich geofluids are located in areas 
mainly characterized by extensional tectonics. Hence, we calculated the kernel density of the distribution of the $\mathrm{CO}_{2}$ rich thermal springs (Waring, 1965) cataloged by Tamburello et al. (2018) and compared with the seismic precursors of our catalog (Figure 4B). A significant part of them is located in areas characterized by deep $\mathrm{CO}_{2}$-rich geofluids and, thus, favourable for geofluid monitoring oriented to revealing ongoing crustal deformation processes. As a matter of fact, these $\mathrm{CO}_{2}$-rich areas correspond to the observed seismic precursors recorded in radon and other gases (Figure 1).

\section{SELECTING PROPER SITES FOR EARTHQUAKE PREPARATION AREAS MONITORING}

The data of the utilized catalog provide constraining factors on future monitoring of pre-seismic crustal deformation processes. Current crustal monitoring strategies imply to set up GNSS stations with the purpose to obtain a statistically significant coverage of territory, usually in the approximate range of 1 station every $20-100 \mathrm{~km}$. Here, we propose to concentrate monitoring efforts in particular areas considered more sensitive to possible earthquake precursors. Data evaluation suggests to take into account also additional parameters like the earthquake depth, the heat flux and the distance from volcanic structures. In this way, the monitored area is better constrained and allow a better identification of possible earthquake preparation areas. In Supplementary Figure S4 of Supplementary Material we show the more favourable areas of the world for monitoring activities. In particular Supplementary Figure S4a-i in Supplementary Material show earthquakes (green dots) characterized by $\mathrm{M} \geq 5.5$ (International Seismological Center, 2020) that occurred in areas affected by relatively high heat flux $\left(\geq 65 \mathrm{~mW} / \mathrm{m}^{2}\right)$ in the depth interval $0-20 \mathrm{~km}$. Pleistocenic and Holocenic volcanic areas (red triangles) are also indicated (Global Volcanism Program, 2013). Clusters of green dots, particularly those ones located within $200-250 \mathrm{~km}$ from volcanic structures represent areas characterized by a relatively higher favourability to detect possible earthquake precursors. These findings may be utilized in the engineering of proper networks oriented to researches in the field of earthquake forecasting.

\section{CONCLUSION}

A review and reprocessing of literature data allowed us to identify potential geological features that would control seismic precursors. These findings allowed to highlight the most suitable places in the world where identifying ongoing crustal deformative and geofluid-related processes before seismic events. We propose that areas with shallow seismicity, high heat flow, and presence of geofluids (e.g. confined aquifers, volcanic fluids, mantle degassing) may facilitate the occurrence of precursory signals. Monitoring deep fluids, such as pore pressure variations in groundwaters, may be carried out using water level, water flow rate and temperature sensors. Water chemical composition may be carried out through manual sampling and chemical sensors if not subjected to significant signal drifting. $\mathrm{CO}_{2}$ and $\mathrm{CH}_{4}$ flow rate may be carried out using manual samplings or automatic groundbased stations (e.g. Cioni et al., 2007), or satellite monitoring (e.g. Tramutoli et al., 2013; Zoran et al., 2016; Ouzounov et al., 2018; Martinelli et al., 2020). Automatic devices able to monitor $\mathrm{CO}_{2}$ fluxes and ${ }^{13} \mathrm{C} /{ }^{12} \mathrm{C}$ parameter may be, in principle, utilized in suitable areas while noble gas analysis may be carried out using suitable automatic devices. Crustal deformations may be monitored through geodetic stations, strainmeters and tiltmeters. InSAR may be helpful to monitor large areas with proper resolution.

Experiences carried out in many countries, particularly in Japan, China, Taiwan and Iceland, indicate that each potential seismogenic fault capable of generating seismic events $>5.5$ ought to be monitored. Geological conditions may vary in different countries; nonetheless, several ground-based stations in the range of 1 every 3,000-10,000 $\mathrm{km}^{2}$ accompanied by data coming from geodetic stations, seismic networks, and satellite observations, could be suitable for crustal deformation monitoring. Koizumi et al. (2004), Chen et al. (2020), Crespi et al. (2020), among others, recently described the feasibility of a similar approach that could benefit from the implementation of geofluid monitoring.

\section{DATA AVAILABILITY STATEMENT}

The original contributions presented in the study are included in the article/Supplementary Material, further inquiries can be directed to the corresponding author.

\section{AUTHOR CONTRIBUTIONS}

GM conceived and wrote the manuscript. GT analyzed the data and produced all the figures. GT also participated in the scientific discussion and revised the text.

\section{ACKNOWLEDGMENTS}

The authors wish to thank HW and $A B$ for their constructive reviews which helped to improve the manuscript and the supplementary material. P. Audet is also thanked for editorial handling.

\section{SUPPLEMENTARY MATERIAL}

The Supplementary Material for this article can be found online at: https://www.frontiersin.org/articles/10.3389/feart.2020.596050/ full\#supplementary-material. 


\section{REFERENCES}

Albarello, D. (2015). State of the art on short-term earthquake forecasting and preparation in Italy: a preface. B. Geofis. Teor. Appl. 56, 71-82. doi:10.4430/ bgta0151

Bernard, P. (2001). From the search of "precursors" to the research on "crustal transients". Tectonophysics 338, 225-232. doi:10.1016/S0040-1951(01)00078-6

Beroza, G. C., and Ellsworth, W. L. (1996). Properties of the seismic nucleation phase. Tectonophysics 261, 209-227. doi:10.1016/0040-1951(96)00067-4

Bodvarsson, G. (1970). Confined fluids as strain meters. J. Geophys. Res. 75 (14), 2711-2718. doi:10.1029/JB075i014p02711

Bowman, D. D., Ouillon, G., Sammis, C. G., Sornette, A., and Sornette, D. (1998). An observational test of the critical earthquake concept. J. Geophys. Res. 103, 24359-24372. doi:10.1029/98JB00792

Bürgmann, R. (2018). The geophysics, geology and mechanics of slow fault slip. Earth Planet Sci. Lett. 495, 112-134. doi:10.1016/j.epsl.2018.04.062

Burov, E. B. (2011). Rheology and strength of the lithosphere. Mar. Petrol. Geol. 28, 1402-1443. doi:10.1016/j.marpetgeo.2011.05.008

Chaves, E. J., and Schwartz, S. Y. (2016). Monitoring transient changes within overpressured regions of subduction zones using ambient seismic noise. Sci. $A d v$., 2, e1501289. doi:10.1126/sciadv.1501289

Chebrov, V. N., Saltykov, V. A., and Serafimova, Yu. K. (2013). Identifying the precursors of large $(M \geq 6.0)$ earthquakes in Kamchatka based on data from the Kamchatka branch of the Russian expert council on earthquake prediction: 1998-2011. J. Volcanol. Seismol. 7, 76-85. doi:10.1134/ S074204631301003X

Chen, W.-P., and Molnar, P. (1983). Focal depths of intracontinental and intraplate earthquakes and their implications for the thermal and mechanical properties of the lithosphere. J. Geophys. Res. 88, 4183-4214. doi:10.1029/ JB088iB05p04183

Chen, Z., Li, Y., Martinelli, G., Liu, Z., Lu, C., and Zhao, Y. (2020). Spatial and temporal variations of $\mathrm{CO}_{2}$ emissions from the active fault zones in the capital area of China. Appl. Geochem. 112, 104489. doi:10.1016/j. apgeochem.2019.104489

Chiodini, G., Cardellini, C., Amato, A., Boschi, E., Caliro, S., Frondini, F., et al (2004). Carbon dioxide Earth degassing and seismogenesis in central and southern Italy. Geophys. Res. Lett. 31, L07615. doi:10.1029/2004GL019480

Cicerone, R. D., Ebel, J. E., and Britton, J. (2009). A systematic compilation of earthquake precursors. Tectonophysics 476 (3-4), 371-396. doi:10.1016/j.tecto. 2009.06.008

Cioni, R., Guidi, M., Pierotti, L., and Scozzari, A. (2007). An automatic monitoring network installed in Tuscany (Italy) for studying possible geochemical precursory phenomena. Nat. Hazards Earth Syst. Sci. 7, 405-416. doi:10. 5194/nhess-7-405-2007

Collettini, C., Niemeijer, A., Viti, C., Smith, S. A. F., and Marone, C. (2011). Fault structure, frictional properties and mixed-mode fault slip behavior. Earth Planet Sci. Lett. 311, 316-327. doi:10.1016/j.epsl.2011.09.020

Crespi, M., Kossobokov, V., Panza, G. F., and Peresan, A. (2020). Space-time precursory features within ground velocities and seismicity in north-Central Italy. Pure Appl. Geophys. 177, 369-386. doi:10.1007/s00024-019-02297-y

Di Giacomo, D., Engdahl, E. R., and Storchak, D. A. (2018). The ISC-GEM earthquake catalogue (1904-2014): status after the extension project. Earth Syst. Sci. Data 10, 1877-1899. doi:10.5194/essd-10-1877-2018

Diggle, P. J. (1985). A kernel method for smoothing point process data. J. R. Stat. Soc. Ser. C Appl. Stat. 34, 138-147. doi:10.2307/2347366

Dobrovolsky, I. P., Zubkov, S. I., and Miachkin, V. I. (1979). Estimation of the size of earthquake preparation zones. Pure Appl. Geophys. 117, 1025-1044. doi:10. 1007/BF00876083

D. Ouzounov, S. Pulinets, K. Hattori, and P. Taylor (2018). Pre-earthquake processes: a multidisciplinary approach to earthquake prediction studies, geophysical monograph. Hoboken, NJ: John Wiley \& Sons, Inc., 234, 365.

Dragoni, M. (1993). The brittle-ductile transition in tectonic boundary zones. Ann. Geofisc. 36, 37-44. doi:10.4401/ag-4282

Fang, Z., Dieterich, J. H., and Xu, G. (2010). Effect of initial conditions and loading path on earthquake nucleation. J. Geophys. Res. 115, B06313. doi:10.1029/ 2009JB006558

Fine, R. A., and Millero, F. J. (1973). Compressibility of water as a function of temperture and pressure. J. Chem. Phys. 59, 5529-5536. doi:10.1063/1.1679903
Frezzotti, M. L., Peccerillo, A., and Panza, G. (2009). Carbonate metasomatism and $\mathrm{CO}_{2}$ lithosphere-astenosphere degassing beneath the Western Mediterranean: an integrated model arising from petrological and geophysical data. Chem. Geol. 262, 108-120. doi:10.1016/j.chemgeo.2009.02.015

Friedmann, H. (1985). Anomalies in the radon content of spring water as earthquake precursor phenomena. Earthq. Pred. Res. 1, 179-189. doi:10. 1016/0040-1951(93)90096-3

Fyfe, W. S., Price, N. J., and Thompson, A. B. (1978). Fluids in the earth's crust. Development Geochemistry. (Amsterdam, Netherlands: Elsevier), 1, 381.

Ghosh, D., Deb, A., and Sengupta, R. (2009). Anomalous radon emission as precursor of earthquake. J. Appl. Geophys. 69, 67-81. doi:10.1016/j.jappgeo. 2009.06.001

Gleeson, T., and Ingebritsen, S. E. (2017). “Toward systematic characterization,” in Crustal permeability. Editors T. Gleeson and S. E. Ingebritsen (New York, NY: John Wiley \& Sons), 395-397.

Global Volcanism Program (2013). in Volcanoes of the world, v. 4.9.0. Editor E Venzke. (Washington, DC: Smithsonian institution). doi:10.5479/si.GVP. VOTW4-2013

Hartmann, J., and Levy, J. K. (2005). Hydrogeological and gasgeochemical earthquake precursors-A review for applications. Nat. Hazards 34 (3), 279-304. doi:10.1007/s11069-004-2072-2

Hauksson, E. (1981). Radon content of groundwater as an earthquake precursor: evaluation of worldwide data and physical basis. J. Geophys. Res. Solid Earth 86 (B10), 9397-9410. doi:10.1029/JB086iB10p09397

Heidbach, O., Rajabi, M., Cui, X., Fuchs, K., Müller, B., Reinecker, J., et al (2018). The World Stress Map database release 2016: crustal stress pattern across scales. Tectonophysics 744, 484-498. doi:10.1016/j.tecto.2018.07.007

Heinicke, J., Fischer, T., Gaupp, R., "otze, G. J., Ko, c. h. U., Konietzky, H., et al (2009). Hydrothermal alteration as a trigger mechanism for earthquakeswarms: the Vogtland/NW Bohemia region as a case study. Geophys. J. Int. 178, 1-13. doi:10.1111/j.1365-246X.2009.04138.x

Huang, Y., Ellsworth, W. L., and Beroza, G. C. (2017). Stress drops of induced and tectonic earthquakes in the central United States are indistinguishable. Sci Adv 3 (8), e1700772-e1700778. doi:10.1126/sciadv.1700772

International Seismological Centre (2020). ISC-GEM earthquake catalogue. Thatcham, United Kingdom: International Seismological Centre. doi:10. 31905/d808b825

Kissin, I. G., and Grinevsky, A. O. (1990). Main features of hydrogeodynamic earthquake precursors. Tectonophysics 178 (2-4), 277-286. doi:10.1016/00401951(90)90154-Z

Koizumi, N., Kitagawa, Y., Matsumoto, N., Takahashi, M., Sato, T., Kamigaichi, O., et al (2004). Preseismic groundwater level changes induced by crustal deformations related to earthquake swarms of the east coast of the Izu Peninsula. Japan, Geophys. Res. Lett. 26, 3509-3512. doi:10.1029/ 2004GL019557

Kreemer, C., Blewitt, G., and Klein, E. C. (2014). A geodetic plate motion and global strain rate model. G-cubed 15, 3849-3889. doi:10.1002/ 2014GC005407

Kreemer, C., Holt, W. E., and Haines, A. J. (2003). An integrated globalmodel of present-day plate motions and plate boundary deformation. Geophys. J. Int. 154, 8-34. doi:10.1046/j.1365-246X.2003.01917.x

Kumpel, H.-J. (1992). About the potential of wells to reflect stress variations within inhomogeneous crust. Tectonophysics 211 (1-4), 317-336. doi:10.1016/00401951(92)90068-H

Lucazeau, F. (2019). Analysis and mapping of an updated terrestrial heat flow data set. G-cubed 20, 4001-4024. doi:10.1029/2019GC008389

Ma, S., Ma, J., and Liu, L. (2002). Experimental evidence for seismic nucleation phase. Chin. Sci. Bull. 47, 769-773. doi:10.1360/02tb9174

Martinelli, G. (2020). Previous, current, and future trends in research into earthquake precursors in geofluids. Geosciences 10, 189. doi:10.3390/ geosciences 10050189

Martinelli, G., and Dadomo, A. (2017). Factors constraining the geographic distribution of earthquake geochemical and fluid-related precursors. Chem. Geol. 469, 176-184. doi:10.1016/j.chemgeo.2017.01.006

Martinelli, G., Facca, G., Genzano, N., Gherardi, F., Lisi, M., Pierotti, L., et al (2020). Earthquake-related signals in Central Italy detected by hydrogeochemical and satellite techniques. Front. Earth Sci. 8, 529. doi:10. $3389 /$ feart.2020.584716 
Matsumoto, N., Kitagawa, Y., and Koizumi, N. (2007). Groundwater-level anomalies associated with a hypothetical preslip prior to the anticipated tokai earthquake: detectability using the groundwater observation network of the geological survey of Japan, AIST. Pure Appl. Geophys. 164, 2377-2396.

Ohnaka, M. (2000). A physical scaling relation between the size of an earthquake and its nucleation zone size. Pure Appl. Geophys. 157, 2259-2282. doi:10.1007/ pl00001084

Ohnaka, M. (1992). Earthquake source nucleation: a physical model for shortterm precursors. Tectonophysics 211, 149-178. doi:10.1016/0040-1951(92) 90057-D

Petraki, E., Nikolopoulos, D., Panagiotaras, D., Cantzos, D., Yannakopoulos, P., Nomicos, C., et al (2015). Radon-222: a potential short-term earthquake precursor. J. Earth Sci. Climatic Change 6, 282. doi:10.4172/2157-7617.1000282

Ping, Z., Guoze, Z., Ji, T., Feng, L., Weihuai, S., Bing, H., et al (2018). Establishment of the ELF network in yunnan and electromagnetic precursory monitoring results of the yangbi Ms 5.1 earthquake on March 27, 2017. Earthq. Res. China 32, 254-264.

Ranalli, G. (1995). Rheology of the earth. London, United Kingdom: Chapman \& Hall, 413.

Rice, J. R., and Cleary, M. P. (1976). Some basic stress diffusion solutions forfluidsaturated elastic porous media with compressible constituents. Rev. Geophys. Space Phys. 14, 227-241. doi:10.1029/RG014i002p00227

Roeloffs, E. (2006). Evidence for aseismic deformation rate changes prior to earthquakes. Annu. Rev. Earth Planet Sci. 34, 591-627. doi:10.1146/annurev. earth.34.031405.124947

Roeloffs, E. (1988). Hydrologic precursors to earthquakes: a review. Pure Appl. Geophys. 126 (2), 177-209. doi:10.1007/BF00878996

Rikitake, T. (1994). Nature of macro-anomaly precursory to an earthquake, J. Phys. Earth 42, 149-163.

Sammonds, P. R., Meredith, P. G., and Main, I. G. (1992). Role of pore fluids in the generation of seismic precursors to shear fracture. Nature 359, 228-230. doi:10. $1038 / 359228 \mathrm{a} 0$

Scholz, C. H. (2010). The mechanics of earthquakes and faulting. New York, NY: Cambridge University Press, 471.

Sibson, R. H. (1983). Continental fault structure and the shallow earthquake source. J. Geol. Soc. London 140, 741-767. doi:10.1144/gsjgs.140.5.0741

Tamburello, G., Pondrelli, S., Chiodini, G., and Rouwet, D. (2018). Global-scale control of extensional tectonics on CO2 earth degassing. Nat. Commun. 9, 4608. doi:10.1038/s41467-018-07087-z

Thomas, D. (1988). Geochemical precursors to seismic activity. Pure Appl. Geophys. 126 (2), 241-266. doi:10.1007/BF00878998

Tiampo, K. F., and Shcherbakov, R. (2012). Seismicity-based earthquake forecasting techniques: ten years of progress. Tectonophysics 522-523, 89-121. doi:10.1016/j.tecto.2011.08.019

Toutain, J.-P., and Baubron, J.-C. (1999). Gas geochemistry and seismotectonics: a review. Tectonophysics 304 (1-2), 1-27. doi:10.1016/S0040-1951(98)00295-9
Tramutoli, V., Aliano, C., Corrado, R., Filizzola, C., Genzano, N., Lisi, M., et al (2013). On the possible origin of thermal infrared radiation (TIR) anomalies in earthquake-prone areas observed using robust satellite techniques (RST). Chem. Geol. 339, 157-168. doi:10.1016/j.chemgeo.2012.10.042

Utsu, T. (2002). "Statistical features of seismicity," in International handbook of earthquake and engineering seismology-Part A. Editors W. H. K. Lee, H. Kanamorui, P. C. Jemmings, and C. Kisslinger (Amsterdam, Netherlands: IASPEI-Academic Press), 719-746.

Wang, C-y., and Manga, M. (2010). Earthquakes and water. Berlin, Germany: Springer-Verlag, 225. doi:10.1007/978-3-642-00810-8

Wang, J-H. (2016). A mechanism causing b-value anomalies prior to a mainshock. Bull. Seismol. Soc. Am. 106, 1663-1671. doi:10.1785/0120150335

Wang, J-H., Chen, K.-C., Leu, P.-L., and Chang, C-H. (2016). Precursor Times of abnormal b-values prior to mainshocks. J. Seismol. 20, 905-919. doi:10.1007/ s10950-016-9567-7

Waring, G. A. (1965). Thermal springs of the United States and other countries of the world-A summary. Washington, DC: United States Geological Survey, 383.

Werner, C., Fischer, T., Aiuppa, A., Edmonds, M., Cardellini, C., Carn, S., et al (2019). "Carbon dioxide emissions from subaerial volcanic regions: two decades in review," in Deep carbon: past to present. Editors B. Orcutt, I. Daniel, and R. Dasgupta (Cambridge, United Kingdom: Cambridge University Press), 188-236.

Woith, H. (2015). Radon earthquake precursor: a short review. Eur. Phys. J. Spec. Top. 224, 611-627. doi:10.1140/epjst/e2015-02395-9

Woith, H., Petersen, G. M., Hainzl, S., and Dahm, T. (2018). Review: can animals predict earthquakes?. Bull. Seismol. Soc. Am. 108 (3), 1031-1045. doi:10.1785/ 0120170313

Wyss, M. (1991). Evaluation of proposed earthquake precursors. Washington, DC.: American Geophysical Union, 94.

Yamashita, T., and Tsutsumi, A. (2018). Involvement of fluids in earthquake ruptures. Berlin, Germany: Springer, 187.

Zoran, M., Savastru, R., and Savastru, D. (2016). Earthquake anomalies recognition through satellite and in-situ monitoring data. European Journal of Remote Sensing 49 (1), 1011-1032. doi:10.5721/EuJRS20164952

Conflict of Interest: The authors declare that the research was conducted in the absence of any commercial or financial relationships that could be construed as a potential conflict of interest.

Copyright (c) 2020 Martinelli and Tamburello. This is an open-access article distributed under the terms of the Creative Commons Attribution License (CC $B Y)$. The use, distribution or reproduction in other forums is permitted, provided the original author(s) and the copyright owner(s) are credited and that the original publication in this journal is cited, in accordance with accepted academic practice. No use, distribution or reproduction is permitted which does not comply with these terms. 